\title{
Isı Yalıtım Malzemelerinin Ses Yalıtım Özelliklerinin Değerlendirilmesi
}

\author{
${ }^{* 1}$ Ahmet Fertelli and ${ }^{2}$ Sinan Aydın \\ ${ }^{1}$ Faculty of Engineering, Department of Mechanical Engineering Sivas Cumhuriyet University, Turkey \\ ${ }^{* 2}$ Faculty of Technology, Department of Mechatronic Engineering Sivas Cumhuriyet University, Turkey
}

\section{Özet}

Günümüzde gürültü kontrolü yaşam kalitesini atrırmada en en önemli faktörlerden birisidir. İnsanların kendi binalarında konforlu ve huzurlu zaman geçirebilmeleri için ses yalıtımın yapılması zorunludur. Bu çalışmada 1sı yalıttmı amacıyla kullanılan EPS, XPS, cam yünü ve taşyünü gibi malzemelerin gürültü düzeyine olan etkileri incelenmiştir. Farklı kanlıklarda yalıtım malzemesi kullanarak ve farklı gürültü düzeyleri $(85 \mathrm{~dB}, 90 \mathrm{~dB}$ ve $100 \mathrm{~dB})$ oluşturularak deneyler yapılmıştır. Yapılan deneyler sonucunda, yalıtım malzemesi kalınlığını artırılması ile gürültü düzeylerinde azalmanın çok fazla değişmediği, lifli malzemelerin kullanılmasının ses yalıtımı açısından daha doğru olduğu görülmektedir. $5 \mathrm{~cm}$ kalınlığındaki yalıtım malzemesi için EPS ve XPS kullanılması durumunda gürültü düzeyinde \% 31,67 - \% 32,51 oranında azalma sağlanırken, cam yünü ve taş yünü kullanılması durumunda \% 37,23 - \% 39 oranında azalma sağlanmaktadır.

Anahtar kelimeler: Gürültü düzeyi, Ses yalıtım malzemesi, Isı yalıtım malzemesi

\section{Evaluation of Sound Insulation Properties of Heat Insulation Materials}

\begin{abstract}
Today, noise control is one of the most important factors in the quality of life. Sound insulation is essential for people to spend a comfortable and peaceful time in their own buildings. In this study, the effects of EPS, XPS, glass wool and rockwool on the noise level were investigated. Experiments were carried out using different insulation materials and different noise levels. As a result of the experiments, it is seen that the decrease in the noise levels does not change much by increasing the thickness of the insulation material and the use of the fiber materials is more accurate in terms of sound insulation. When EPS and XPS are used for insulation material of $5 \mathrm{~cm}$ thickness, a reduction of $31.67 \%-32.51 \%$ is achieved in noise level, while in the case of using glass wool and rock wool, a reduction of $37.23 \%$ $39 \%$ is achieved.
\end{abstract}

Key words: Noise level, Sound insulation material, Heat insulation material.

\section{Giriş}

Plansız şehirleşmenin ve insanların belirli bölgelerde yoğun yaşamalarından dolayı gürültü, insan sağlı̆̆ına ve konforuna zarar veren parametrelerden birisi olarak tanımlanır. Gürültü kişiler üzerinde rahatsızlık oluşturmakla birlikte, insanlar üzerinde davranış bozuklukları, duyma

*Corresponding author: Address: Faculty of Technology, Department of Mechatronic Engineering, Sivas Cumhuriyet University, TURKEY. E-mail address: sinancan@cumhuriyet.edu.tr, Phone: +903462191010 
kayıpları gibi fizyolojik, psikolojik ve performans yönünden olumsuz etkiler oluşturur [1]. Gürültüler 0-65 dBA aralığında konforsuzluk, rahatsızlık, sıkılma duygusu, kızgınlık, konsantrasyon bozukluğu, uyku bozukluğu, 65-90 dBA aralığında fizyolojik gürültü, kalp atışının değişimi, solunumun hızlanması, beyindeki basıncın azalması, 90-120 dBA III. derecedeki gürültüler ise fizyolojik gürültü ve bas ağrısı oluşturmaktadır [1]. Bina içerisine iletilen gürültü, oluş biçimi ve yayılma ortamı dikkate alındığında hava doğuşumlu ve yapı doğuşumlu olmak üzere iki şekilde oluşur [2]. Hoparlör sesi ve taban üzerinde yürümeden kaynaklı oluşan sesler her ikisine de örnek gösterilebilir. Ortak yapı elemanları üzerindeki boşluklardan oluşan akustik sızıntılar, hava doğuşumlu gürültü olarak değerlendirilir [2]. Çevre ve Şehircilik Bakanlığ tarafından yayınlanan 31 Mayıs 2017 tarihli 30082 sayılı "Binaların Gürültüye Karşı Korunması” hakkındaki yönetmelik, her türlü yapı ve binanın kullanımında insanların maruz kalacağı, binaların dışından veya içinden kaynaklanan gürültülerin, kişilerin huzur ve sükûnuna, beden ve ruh sağlığına olumsuz etkilerini en aza indirecek iyi işitme ve algılama koşullarının sağlanması için, uyulacak kuralların belirlenmesi ve gürültülerin kontrol edilmesi amacıyla alınacak önlemleri ve tasarım değerlerini belirlemiştir [3]. Yönetmelik gereği tüm binalarda ses yalıtımı zorunlu hale getirilmiş ve belirli konfor değerlerinin ses yalıtımı ile sağlanması hedeflenmiştir. Bu amaçla, akustik simülasyon programı yardımıyla bir konservatuvar binasında analizler yapılmış, gürültü yönetmeliğinin gerektirdiği standartlara uyup uymadığı incelenmiştir. Hesaplamalarda yapının bulunduğu bölge, hacim ve özellikleri dikkate alınarak ses yalıtımı değerlerini sağlayan kesitler belirlemiştir [4]. Doğal lifler ucuz, yerli, bol, çevre dostu olması nedeniyle ses yalıtımında kullanılmaktadır. Odun, kenaf, pamuk, keten, kabak, palmiye, çay yaprağı, yün vb. naturel liflerin yalıtım malzemesi olarak kullanılabilirliği için ses yutma değerleri deneysel olarak ölçülmüştür.

Kalınlık ile frekans arasında doğru orantılı artış tespit edilmiştir [5]. Binalardaki betonarme elemanlardan oluşan gürültü ile bir ve çok katmanlı ara duvarların ses geçirmezliği incelenmiştir. Ses yalıtımı, duvar elemanların yoğunluğuna göre farklı şekillerde yerleştirilerek ses geçirmezliği ölçülmüş ve yükseltilmesi için çeşitli alternatif ve öneriler sunulmuştur [6].

Bu çalışmada, şu anda Enerji Verimliliği yönetmeliği gereği ısı yalıtımı amacıyla kullanılan çeşitli 1sı yalıtım malzemelerinin ses yalıtım özellikleri incelenmiştir. Mevcutta kullanılan EPS, XPS, cam yünü ve taşyünü 1sı yalıtım malzemeleri ile yalıtılmış kapalı bir alan içerisinde iç ortamda oluşturulan farklı gürültü düzeylerindeki azalma miktarları incelenmiştir.

\section{Malzemeler ve Yöntem}

Is1 yalıtımı amacıyla kullanılan EPS, XPS, cam yünü ve taşyünü 1S1 yalıtım malzemelerinin ses yalıtım özellikleri incelemek için, $500 \mathrm{~mm} \times 500 \mathrm{~mm} \times 500 \mathrm{~mm}$ boyutlarında oluşturulan kapalı bir mahal, içeriden $3 \mathrm{~cm}, 5 \mathrm{~cm}$ ve $8 \mathrm{~cm}$ kalınlıklarında tamamen yalıtılmıştır (Şekil 1). İç ortamda hoparlör ile oluşturulan gürültü düzeyleri $85 \mathrm{~dB}, 90 \mathrm{~dB}$ ve $100 \mathrm{~dB}$ 'dir. Mahalin tüm yan kenarlarından (A1, A2, A3 ve A4 ) eşit olacak şekilde üçer adet nokta belirlenerek, her kenara ait üç noktadan Brüel\&Kjaer Hand-held ses ölçüm cihazı ile ölçüm yapılıp değerlerin ortalaması alınmıştır. 


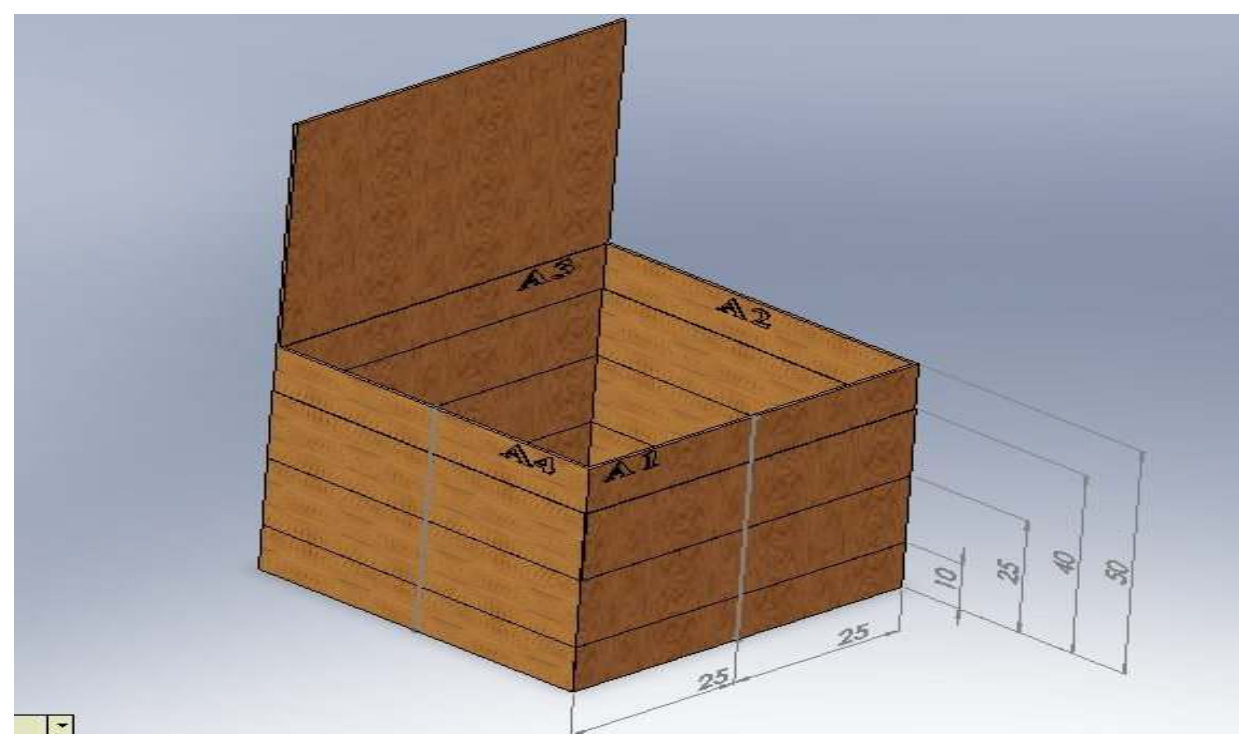

Şekil 1. Ölçümler için yapılan kutu
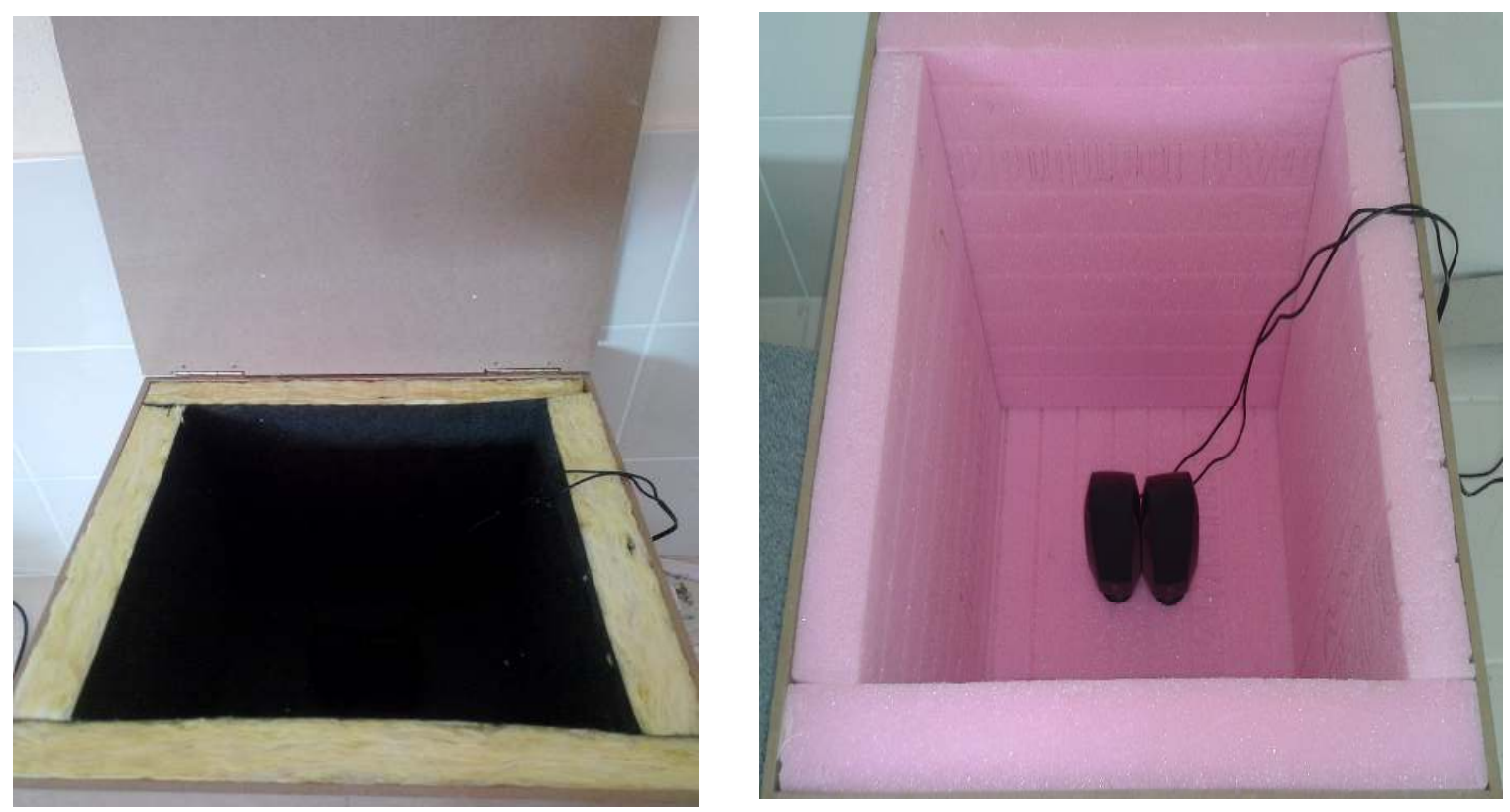

Şekil 2. Yalıtım malzemeleri

Kullanılan 1sı yalıtım malzemelerinden EPS, pentanın buharlaştırılmasıyla elde edilen katı köpük halinde termoplastik, kapalı gözenekli ve 1sı iletim katsayısı 0,031 - 0,037 W/m.K, yoğunluğu 15 $-75 \mathrm{~kg} / \mathrm{m}^{3}$ arasında olan bir $1 \mathrm{~s} 1$ yalıtım malzemesidir [7,8]. XPS yalıtım malzemesi EPS'ye benzemekle beraber, şişirme malzemesi ilave edilerek polistiren tanelerinin levha şekline dönüştürülmesi ile üretilmektedir. Yoğunlukları 25-50 kg/m³, özgül 1sısı 1,3 -1,7 kJ/kg.K, 1sı iletim katsayıları ise 0,028-0,036 W/m.K arasında değişmektedir [7]. Cam yünü 1300-1450 ${ }^{\circ} \mathrm{C}^{\prime}$ de doğal 
silis kumu ve cam karıştırılarak üretilen bir 1sı ve ses yalıtımı malzemesidir [7]. Santrifüj işlemi ile liflere dönüşüm sağlanırken, fenolik reçineler ilave edilerek lifler bağlanır [7,9]. Yoğunlukları 10$120 \mathrm{~kg} / \mathrm{m}^{3}$ arasında değişirken, 1 sı iletim katsayısı değeri $0,040 \mathrm{~W} / \mathrm{m} . \mathrm{K}$ ' dır [7, 10, 11]. İnorganik hammaddeler olan dolomit, bazalt ve diyabaz gibi birkaç çeşit taşların $1400{ }^{\circ} \mathrm{C}-1600{ }^{\circ} \mathrm{C}$ sicaklıkta eritilip elyaf haline getirilmesi sonucu üretilen taşyünü bir 1sı ve ses yalıtım malzemesidir [10]. Reçine ve nişasta gibi bağlayıcılar kullanılarak birbirine bağlanıp lifleri elde edilir [10]. Yoğunluğu $20-200 \mathrm{~kg} / \mathrm{m}^{3}$ arasında değişirken, 1 sı iletim katsayıları ise 0,033-0,040 W/m.K arasındadır [10].

\section{Bulgular ve Tartışma}

Ölçüm yapılan tüm yüzeylerde yapılan gürültü seviyelerinin ortalaması birbirine oldukça yakındır. Şekil 3'de kapalı hacim içerisine $3 \mathrm{~cm}, 5 \mathrm{~cm}$ ve $8 \mathrm{~cm}$ kalınlığında XPS yalıtım malzemesi yerleştirilmesi durumunda dışarıdan ölçülen gürültü düzeyleri gösterilmektedir. $3 \mathrm{~cm}$ kalınlıkta 85 $\mathrm{dB}$ değerindeki gürültü düzeyi $57,16 \mathrm{~dB}, 90 \mathrm{~dB}$ 'deki değer 62,95 dB ve $100 \mathrm{~dB}$ 'deki değer $72 \mathrm{~dB}$ seviyelerine kadar azalmıştır. Kalınlığın artırılmasıyla tüm gürültü seviyeleri için hemen hemen aynı sonuçlar elde edilmiştir.
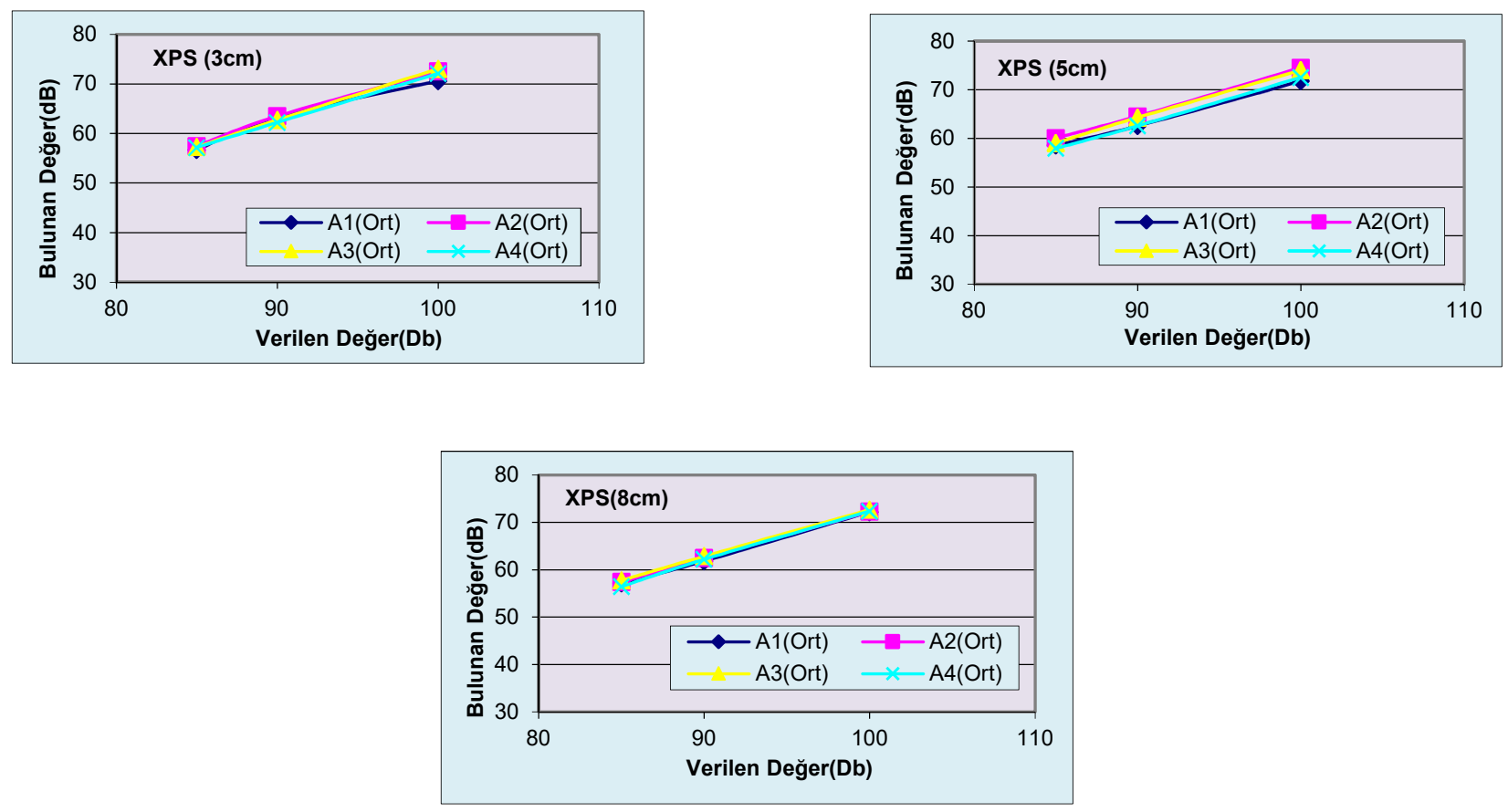

Şekil 3. Farklı kalınlıklardaki XPS yalıtım malzemesi için elde edilen gürültü değerleri

Farklı kalınlıklarda $(3 \mathrm{~cm}, 5 \mathrm{~cm}$ ve $8 \mathrm{~cm})$ EPS yalıtım malzemesi kullanılması durumunda elde edilen gürültü değerleri Şekil 4'de gösterilmektedir. $3 \mathrm{~cm}$ kalınlıkta yalıtım kullanılması durumunda $85 \mathrm{~dB}, 90 \mathrm{~dB}$ ve $100 \mathrm{~dB}$ için sırasıyla 58,44 dB, 62,9 dB ve 73,6 3dB gürültü değerleri ölçülmüştür. EPS ile ses yalıtımı XPS yalıtımına göre daha yetersiz gibi görünse de değerler arasındaki farklılıklar çok azdır. EPS kullanılması durumunda da, kalınlığın artırılması ses yalıtımında önemli bir değişiklik sağlamamıştır. Yalıtım malzemesinin $3 \mathrm{~cm}$ ve $8 \mathrm{~cm}$ kalınlıkta kullanılması durumunda gürültü düzeyindeki azalma \%3,4 seviyesinde gerçekleşmektedir. 

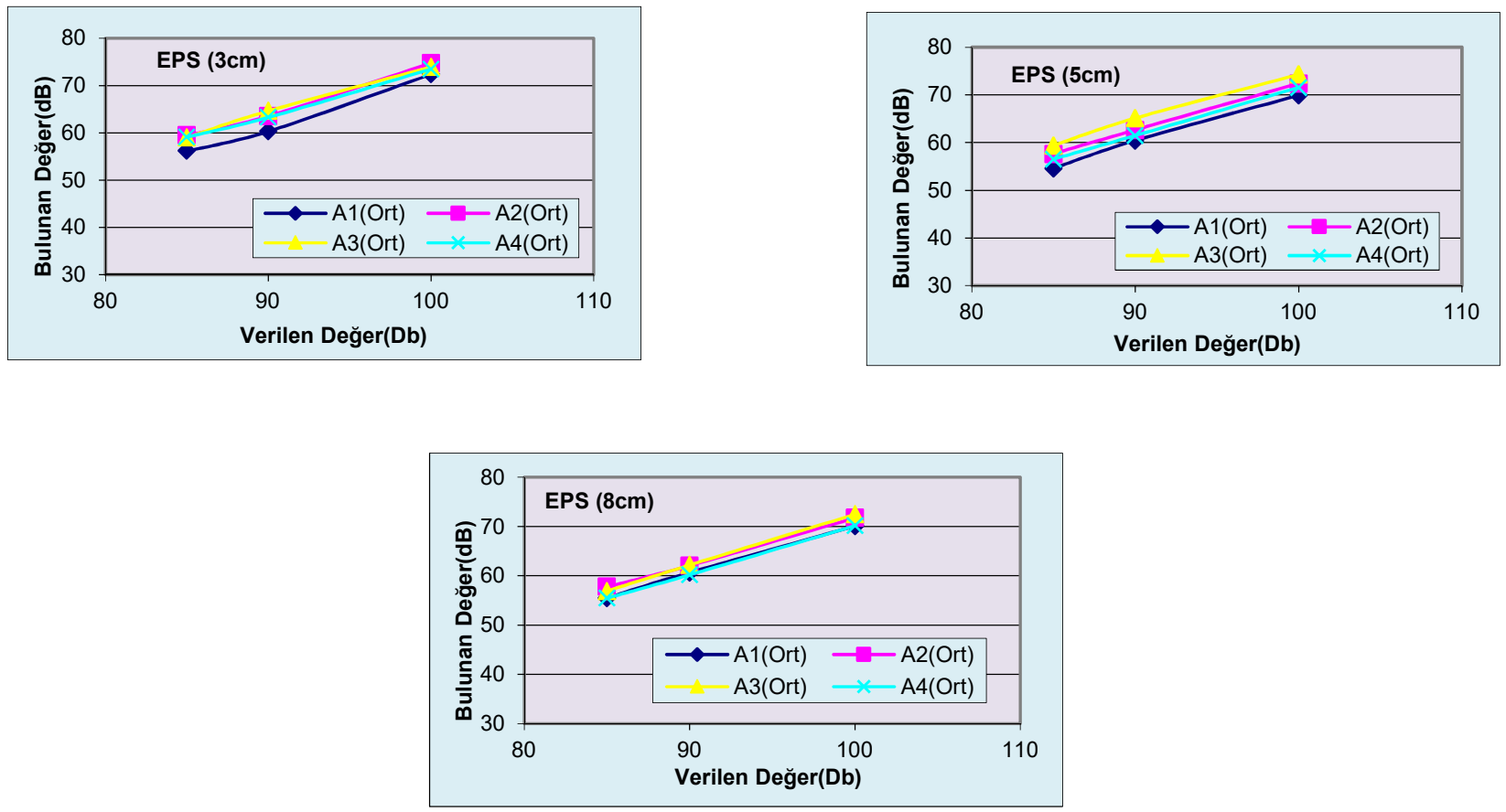

Şekil 4. Farklı kalınlıklardaki EPS yalıtım malzemesi için elde edilen gürültü değerleri
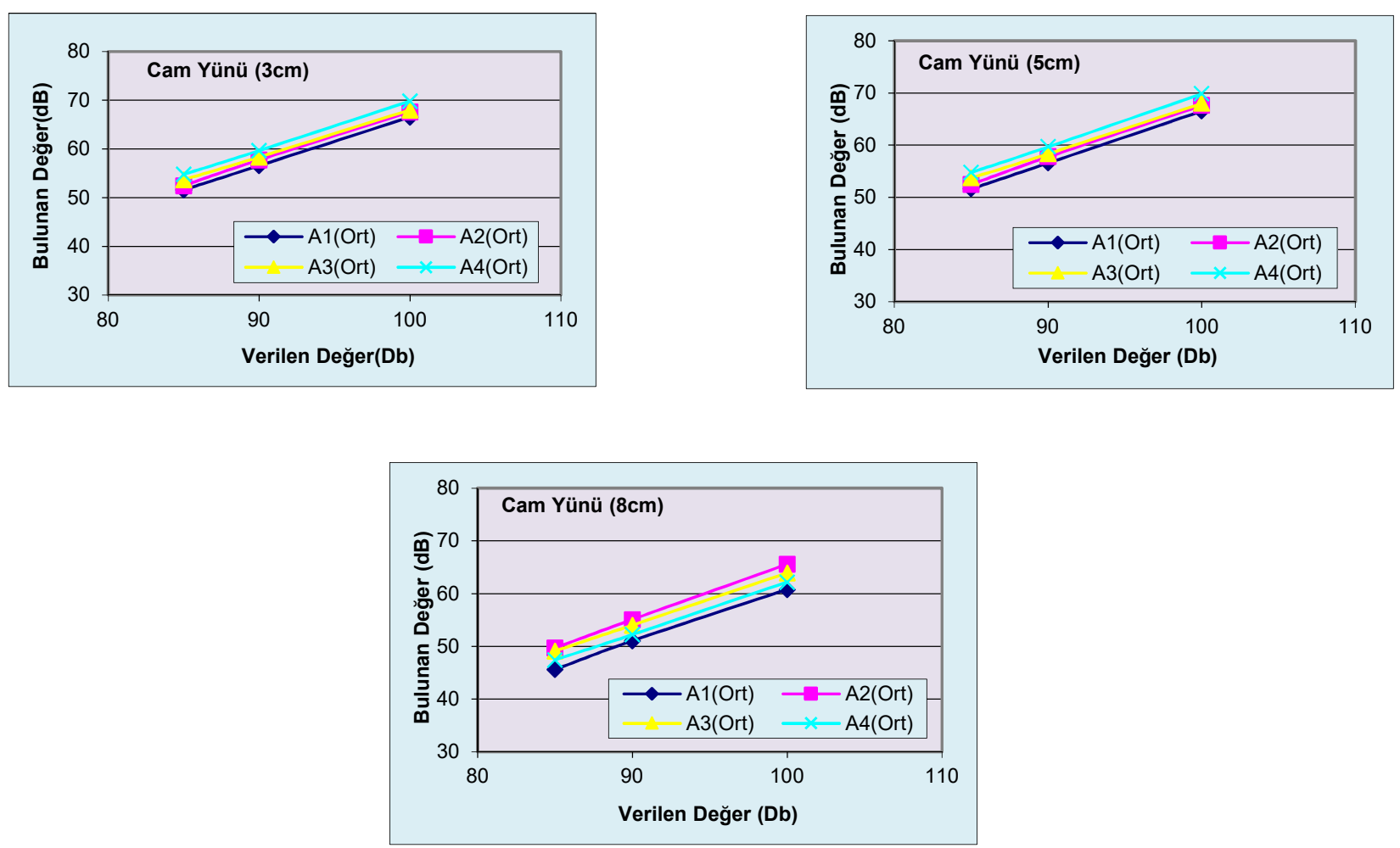

Şekil 5. Farklı kalınlıklardaki cam yünü yalıtım malzemesi için elde edilen gürültü değerleri 
Cam yünü ve taş yünü gibi lifli yalıtım malzemelerinin $3 \mathrm{~cm}, 5 \mathrm{~cm}$ ve $8 \mathrm{~cm}$ kalınlıklarında kullanılması durumunda elde edilen gürültü değerleri Şekil 5 ve Şekil 6'da gösterilmektedir. $3 \mathrm{~cm}$ kalınlıkta $85 \mathrm{~dB}, 90 \mathrm{~dB}$ ve $100 \mathrm{~dB}$ gürültü düzeyleri için cam yününde sırasıyla ortalama 53,13 dB, $58,08 \mathrm{~dB}$ ve $67,99 \mathrm{~dB}$ elde edilirken, taş yününde $52,05 \mathrm{~dB}, 56,62 \mathrm{~dB}$ ve $65 \mathrm{~dB}$ değerleri elde edilmiştir. Gürültü düzeyi arttıkça taş yünündeki ses yalıtım etkisi de artmaktadır. Her iki malzeme için de yalıtım kalınlığının 5 cm'ye çıkarılması ile $3 \mathrm{~cm}$ kalınlığında elde edilen ses düzeyleri yaklaşık aynıdır. $8 \mathrm{~cm}$ kalınlıkta tüm gürültü düzeylerinde cam yünü ile taş yünü için birbirine yakın değerler elde edilirken, aynı kalınlıktaki XPS'e göre cam yünü \% 6,95 taş yünü ise \% 9,35 daha iyi ses yalıtımı sağlamıştır.
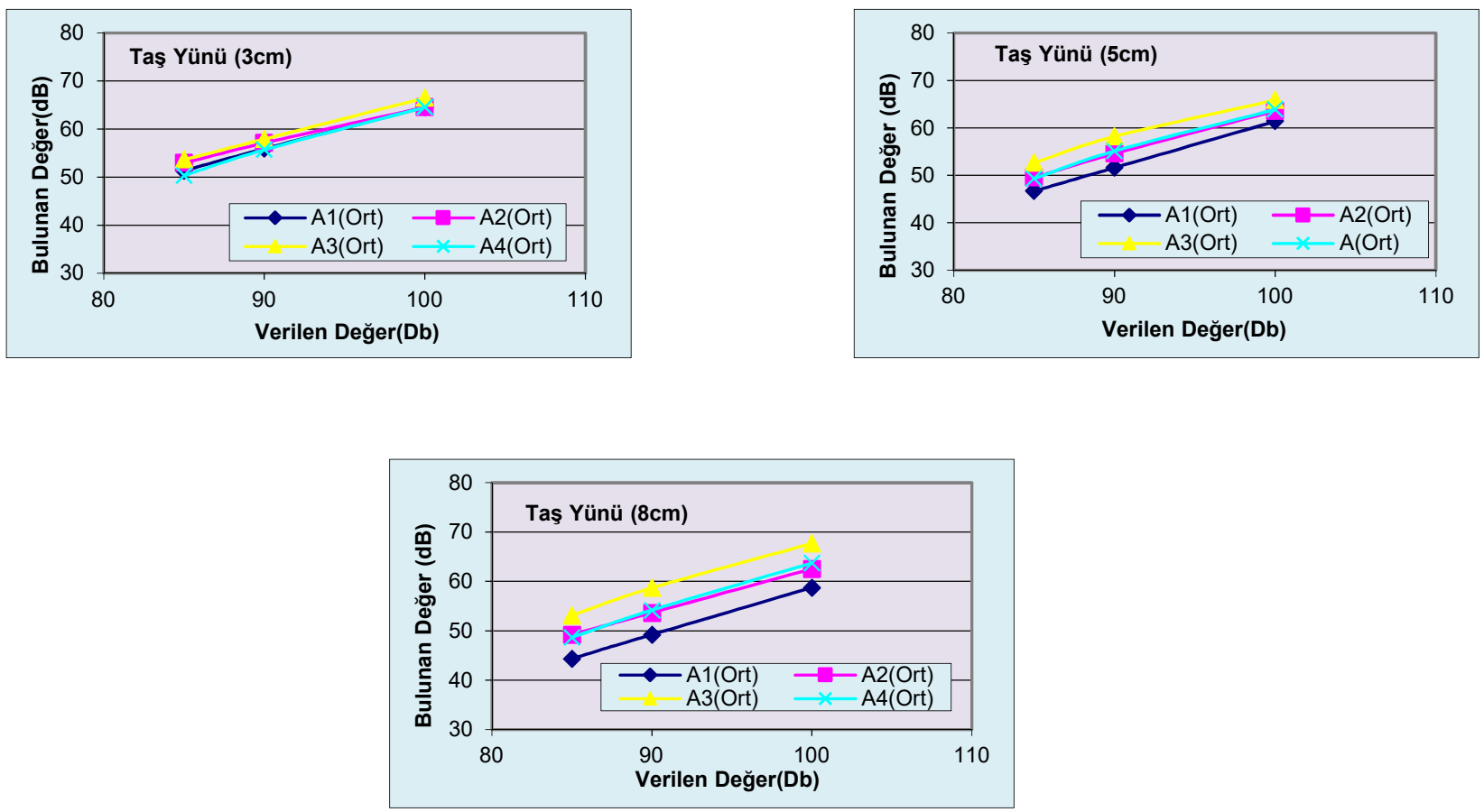

Şekil 6. Farklı kalınlıklardaki taş yünü yalıtım malzemesi için elde edilen gürültü değerleri

\section{Sonuçlar}

Yapılan çalışmada, günümüzde tüm binalarda yaygın olarak kullanılan EPS, XPS, cam yünü ve taşyünü 1sı yalıtım malzemelerinin ses yalıtım özellikleri, farklı düzeylerde oluşturulan gürültü düzeylerine göre incelenmiştir. Yapılan deneyler sonucunda, yalıtım malzemesi kalınlığını artırılması ile gürültü düzeylerinde azalmanın çok fazla değişmediği, lifli malzemelerin kullanılmasının ses yalıtımı açısından daha doğru olduğu görülmektedir. $5 \mathrm{~cm}$ kalınlığındaki yalıtım malzemesi için EPS ve XPS kullanılması durumunda gürültü düzeyinde \% 31,67 - \% 32,51 oranında azalma sağlanırken, cam yünü ve taş yünü kullanılması durumunda \% 37,23 - \% 39 oranında azalma sağlanmaktadır. 


\section{Kaynaklar}

[1] http://www.ode.com.tr/ses-yalitimi

[2] Çalışkan, M. Ses yalıtımı. 4DuvarKnauf 2011; 41: 26-30.

[3] Çevre ve Şehircilik Bakanlığı. Binaların Gürültüye Karşı Korunması Hakkında Yönetmelik; http://www.resmigazete.gov.tr/eskiler/2017/05/20170531-7.htm (Erişim Tarihi: 31. 05.2017).

[4] Untuç B., Akdağ N.Y., Yapılarda Gürültü Denetimi: Bir Örnek Kapsamında Değerlendirmeler, Artium 2017; 5(2):11-21

[5] Kaya A.İ., Dalgar T., Ses Yalıtımı Açısından Doğal Liflerin Akustik Özellikleri, 4. Ulusal Meslek Yüksekokulları Sosyal Ve Teknik Bilimler Kongresi ; 11-13 Mayıs 2017, Burdur.

[6] Abdülrahimov R., Abdülrahimova R., Çok Katlı Endüstrileşmiş Yapı Sistemlerinde Ses Geçirmezliğin Belirlenmesi, IV. Ulusal Tesisat Mühendisliği Kongresi ve Sergisi 1999: 4-7 Kasım 1999, İzmir.

[7] Arslan M.A., Aktaş M., İnşaat Sektöründe Kullanılan Yalıtım Malzemelerinin Isı ve Ses Yalıtımı Açısından Değerlendirilmesi, Journal of Polytechnic 2018;21(2):299-320.

[8] Fangueiro R. Fibrous and composite materials for civil engineering applications. Woodhead Publishing Limited Cambridge, 2011.

[9] Schiavoni S., D'Alessandro F., Bianchi F., Asdrubali F., Insulation materials for the building sector: A review and comparative analysis, Renewable and Sustainable Energy Reviews 2016; 62: 988-1011.

[10] Ülker S., Isı Yalıtım Malzemelerinin Özelliklerinin Uygulamaya Etkileri, Yüksek Lisans Tezi, İstanbul Teknik Üniversitesi Fen Bilimleri Enstitüsü 2009.

[11] Tatematsu K., Hirota T., Suzuki H., Taniguchi M., Nunoi Y., Uzawa T., Influence of temperature and moisture on aging of glass wool, Journal of Environmental Engineering 2014;79: 753-62. 